Braz J Med Biol Res, August 2012, Volume 45(8) 777-783

doi: 10.1590/S0100-879X2012007500105

Effects of high-intensity intermittent training on carnitine palmitoyl transferase activity in the gastrocnemius muscle of rats

L.C. Carnevali Jr., R. Eder, F.S. Lira, W.P. Lima, D.C. Gonçalves, N.E. Zanchi, H. Nicastro, J.M. Lavoie and M.C.L. Seelaender

The Brazilian Journal of Medical and Biological Research is partially financed by

\section{且CNPq}

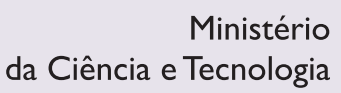

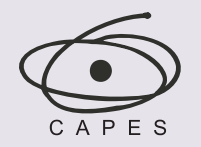

Ministério da Educação
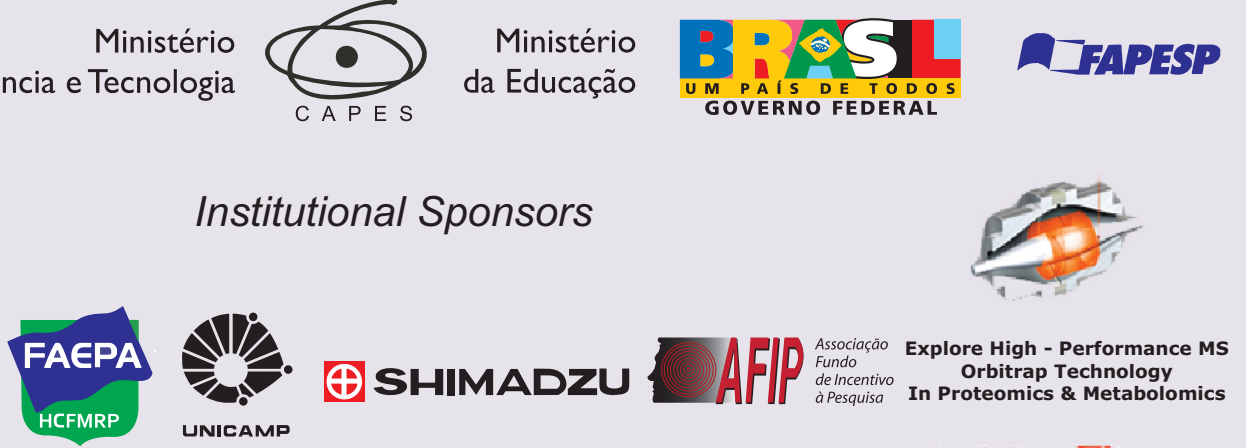

Institutional Sponsors

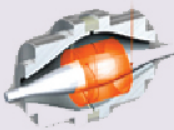

Ф SHIMADZU UNICAMP

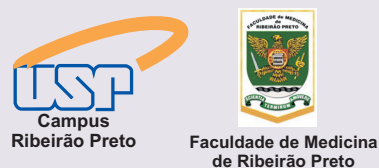

de Ribeirão Preto 


\title{
Effects of high-intensity intermittent training on carnitine palmitoyl transferase activity in the gastrocnemius muscle of rats
}

\author{
L.C. Carnevali Jr. ${ }^{1,6}$, R. Eder ${ }^{1}$, F.S. Lira ${ }^{1}$, W.P. Lima ${ }^{1,5}$, D.C. Gonçalves ${ }^{1}$, \\ N.E. Zanchi ${ }^{2,3}$, H. Nicastro ${ }^{2}$, J.M. Lavoie ${ }^{4}$ and M.C.L. Seelaender ${ }^{1}$ \\ ${ }^{1}$ Grupo de Biologia Molecular da Célula, Instituto de Ciências Biomédicas, \\ Universidade de São Paulo, São Paulo, SP, Brasil \\ 2Laboratorio de Nutrição e Metabolismo Aplicado à Atividade Motora, Escola de Educação Física e Esporte, \\ Universidade de São Paulo, São Paulo, SP, Brasil \\ ${ }^{3}$ Centro de Pesquisa do Genoma Humano, Instituto de Ciências Biomédicas, \\ Universidade de São Paulo, São Paulo, SP, Brasil \\ ${ }^{4}$ Department of Kinesiology, University of Montreal, Montreal, Canada \\ ${ }^{5}$ Instituto Federal de Educação, Ciência e Tecnologia de São Paulo, São Paulo, SP, Brasil \\ ${ }^{6}$ Centro Universitário Ítalo-Brasileiro (Unítalo), São Paulo, SP, Brasil
}

\begin{abstract}
We examined the capacity of high-intensity intermittent training (HI-IT) to facilitate the delivery of lipids to enzymes responsible for oxidation, a task performed by the carnitine palmitoyl transferase (CPT) system in the rat gastrocnemius muscle. Male adult Wistar rats (160-250 g) were randomly distributed into 3 groups: sedentary (Sed, N = 5), HI-IT ( $N=10)$, and moderate-intensity continuous training (MI-CT, $\mathrm{N}=10$ ). The trained groups were exercised for 8 weeks with a $10 \%(\mathrm{HI}-\mathrm{IT})$ and a $5 \%(\mathrm{MI}-\mathrm{CT})$ overload. The HI-IT group presented $11.8 \%$ decreased weight gain compared to the Sed group. The maximal activities of CPT-I, CPT-II, and citrate synthase were all increased in the HI-IT group compared to the Sed group (P<0.01), as also was gene expression, measured by RT-PCR, of fatty acid binding protein (FABP; $\mathrm{P}<0.01$ ) and lipoprotein lipase (LPL; P < 0.05 ). Lactate dehydrogenase also presented a higher maximal activity $\left(\mathrm{nmol} \cdot \mathrm{min}^{-1} \cdot \mathrm{mg} \mathrm{protein}^{-1}\right)$ in $\mathrm{HI}-\mathrm{IT}$ (around $\left.83 \%\right)$. We suggest that 8 weeks of HI-IT enhance mitochondrial lipid transport capacity thus facilitating the oxidation process in the gastrocnemius muscle. This adaptation may also be associated with the decrease in weight gain observed in the animals and was concomitant to a higher gene expression of both FABP and LPL in HI-IT, suggesting that intermittent exercise is a "time-efficient" strategy inducing metabolic adaptation.
\end{abstract}

Key words: High-intensity intermittent training; Lipid metabolism; Carnitine palmitoyl transferase

\section{Introduction}

High-intensity intermittent training (HI-IT) is characterized by repeated bouts of brief near-maximal or maximal intensity work, interspersed with periods of recovery (rest or low-intensity work) (1) and is known to be a potent stimulus leading to metabolic adaptation in skeletal muscle (2). A wide range of adaptations has been described for carbohydrate metabolism in response to $\mathrm{HI}-\mathrm{IT}$, including increased glycogen content (3), and increased lactate transport capacity (4). In contrast, HI-IT is generally thought to be less effective on the capacity of muscle to deliver lipids to mitochondria (3).
Few studies have described the alterations of muscle fat metabolism during intermittent exercise, despite the fact that most collective sports are of an intermittent nature, as reviewed by Boutcher in 2011 (5). Moreover, intermittent physical activity is associated with a reduced risk of morbidity and mortality from cardiovascular diseases, and cumulative short bouts of repetitive exercise are thought to mimic the effects of longer bouts of exercise (5). Since fat metabolism disorders are closely associated with the development of cardiovascular diseases, it becomes imperative to better understand the metabolic response to HI-IT.

Correspondence: M.C.L. Seelaender, Instituto de Ciências Biomédicas, USP, Av. Prof. Lineu Prestes, 1524, 05508-900 São Paulo, SP, Brasil. Fax: +55-11-3091-7402. E-mail: seelaend@icb.usp.br

Received March 3, 2011. Accepted May 16, 2012. Available online June 29, 2012. Published August 3, 2012. 
There is recent evidence that HI-IT may indeed induce adaptations in lipid metabolism and may represent a timeefficient strategy to induce muscle adaptation similar to that elicited by continuous endurance training (6). However, the wide variations in HI-IT exercise protocols adopted in the literature make it difficult to identify the effect of this type of exercise upon specific aspects of lipid metabolism. We compared the adaptations in lipid metabolism-associated proteins in $\mathrm{HI}-\mathrm{IT}$ with those resulting from moderate-intensity continuous training (MI-CT) in an animal model. Ahigher rate of fatty acid utilization by skeletal muscle may be achieved by the enhancement of maximal activity of the carnitine palmitoyltransferase (CPT) complex, which is considered to be the key regulatory step in the transport of long-chain fatty acids (7).

Thus, the objective of the present study was to investigate the response of the CPT complex to HI-IT and to compare it to the response elicited by MI-CT in sedentary (Sed) control animals. The gene expression of some important muscle proteins associated with muscle lipid oxidative capacity, including peroxisome proliferator-activated receptor $\alpha$ and $\beta$ (PPAR $\alpha$ ), fatty acid binding protein (FABP) and lipoprotein lipase (LPL) was examined.

\section{Material and Methods}

\section{Animals}

Male adult Wistar rats (160-250 g) obtained from Instituto de Ciências Biomédicas, Universidade de São Paulo, were maintained on a 12-h light/12-h dark cycle (lights on at 7:00 am) under controlled temperature conditions (23 $\pm 1^{\circ} \mathrm{C}$ ), receiving water and food (commercial chow, Nuvilab $^{\circledR}$, Nuvital, Brazil) ad libitum. Animals were randomly divided into the following groups: Sed $(\mathrm{N}=5)$, HI-IT ( $N=$ $10)$ and MI-CT $(N=10)$. The animals were euthanized by decapitation $24 \mathrm{~h}$ after the last exercise bout. The Ethics Committee for Animal Research of Instituto de Ciências Biomédicas, USP, approved the procedures used (protocol
\#148/2001), which were carried out in accordance with the ethical principles stated by the Brazilian College of Animal Experimentation.

\section{Experimental design}

Weight gain, muscle lipid content, plasma lactate, and the activity of the proteins related to mitochondrial longchain fatty acids transport (CPT-I and -II), oxidation (citrate synthase) and glycolysis (lactate dehydrogenase), as well as the mRNA expression of CPT-I, CPT-II, FABP, LPL, PPAR $\alpha, P P A R \beta$, and peroxisome proliferator-activated receptor- $\gamma$ coactivator-1 $\alpha$ (PGC1- $\alpha$ ) were assessed in the gastrocnemius of trained rats submitted to HI-IT. The results were compared to those of the Sed group and the MI-CT group.

All training protocols were performed in a swimming system consisting of 10 individual PVC chambers of 100 x $60 \times 60 \mathrm{~cm}$, with a water temperature of $31 \pm 1^{\circ} \mathrm{C}$ for 8 weeks, after 2 weeks of adaptation, 5 days a week. The swimming training model was chosen over treadmill running because it induces higher recruitment of muscle fibers from the gastrocnemius rather than from the soleus, as previously described (8). Increasing weight loads attached to the tail were adopted so as to reach a maximum of $10 \%$ of total body weight for the HI-IT protocol and $5 \%$ of total body weight for the MI-CT protocol. For HI-IT, the intensity of effort corresponded to $\sim 100 \% \mathrm{VO}_{2} \max (8)$ and the lactate threshold was achieved with extra loads of 5-6\% of total body weight (9). For MI-IT, the exercise intensity corresponded to $\sim 65 \%$ $\mathrm{VO}_{2}$ max. This intensity of effort was assured by constant evaluation of the adaptations to the overweight percentage related to body mass (10). A complete description of the two training protocols is provided in Table 1.

\section{Analytical procedures}

Body weight was measured every week, always at the same time of day. Plasma lactate concentration was measured with a lactate analyzer (YSI 1500 Sport, YSI

Table 1. High-intensity intermittent training (HI-IT) and moderate-intensity continuous training (MI-CT) protocols.

\begin{tabular}{|c|c|c|c|c|c|c|c|c|c|c|}
\hline \multicolumn{5}{|c|}{ HI-IT } & \multicolumn{6}{|c|}{$\mathrm{Ml}-\mathrm{CT}$} \\
\hline Week $^{*}$ & Bouts & $\begin{array}{l}\text { Activity and } \\
\text { rest duration }\end{array}$ & Overload & Total time & Day/week & Overload & Time & Day/week & Overload & Time \\
\hline 3rd week & 11 & $1 \mathrm{~min}: 1 \mathrm{~min}$ & $10 \% \mathrm{BW}$ & $22 \mathrm{~min}$ & 1st day & $0 \% \mathrm{BW}$ & $30 \mathrm{~min}$ & 7th day & $3 \% \mathrm{BW}$ & $50 \mathrm{~min}$ \\
\hline 4th week & 12 & $1 \mathrm{~min}: 1 \mathrm{~min}$ & $10 \% \mathrm{BW}$ & $24 \mathrm{~min}$ & 2nd day & $0 \% \mathrm{BW}$ & $40 \mathrm{~min}$ & 8th day & $3 \% \mathrm{BW}$ & $60 \mathrm{~min}$ \\
\hline 5th week & 13 & $1 \mathrm{~min}: 1 \mathrm{~min}$ & $10 \%$ BW & $26 \min$ & 3rd day & $1 \% \mathrm{BW}$ & $30 \mathrm{~min}$ & 9th day & $4 \% \mathrm{BW}$ & $60 \mathrm{~min}$ \\
\hline 6th week & 14 & $1 \mathrm{~min}: 1 \mathrm{~min}$ & $10 \% \mathrm{BW}$ & $28 \mathrm{~min}$ & 4th day & $1 \% B W$ & $40 \mathrm{~min}$ & 10th day & $5 \%$ BW & $60 \mathrm{~min}$ \\
\hline 7th week & 15 & $1 \mathrm{~min}: 1 \mathrm{~min}$ & $10 \% \mathrm{BW}$ & $30 \mathrm{~min}$ & 5th day & $2 \% B W$ & $40 \mathrm{~min}$ & $3 r d$ to & $5 \%$ BW & $60 \mathrm{~min}$ \\
\hline 8th week & 15 & $1 \mathrm{~min}: 1 \mathrm{~min}$ & $10 \% \mathrm{BW}$ & $30 \mathrm{~min}$ & 6th day & $2 \% \mathrm{BW}$ & $50 \mathrm{~min}$ & 8th week & (5 times/week) & \\
\hline
\end{tabular}

*HI-IT was preceded by 2 weeks of an adaptation protocol. Overload was progressively increased until reaching 10 bouts and $10 \%$ of body weight (BW). 
Life Sciences, USA) on the last day of training before the beginning of exercise and after the 5th and last bout of exercise (HI-IT) and at $0 \mathrm{~min}$, 30th min and after the training session (MI-CT), as described by Gobatto et al. (9). Plasma lactate concentration is reported as means \pm SEM in $\mu \mathrm{mol} / \mathrm{mL}$ plasma.

Citrate synthase activity was measured as described by Zammit et al. (11). Muscles were homogenized (1:20, $\mathrm{v} / \mathrm{v}$ ) in a buffer consisting of $25 \mathrm{mM}$ Tris- $\mathrm{HCl}$ and $1 \mathrm{mM}$ EDTA, pH 7.4. After centrifugation for $1 \mathrm{~min}$ at $2000 \mathrm{rpm}$ the supernatant was collected and $80 \mu \mathrm{L}$ was added to $890 \mu \mathrm{L}$ of the assay mixture, $\mathrm{pH} 8.0$, which consisted of $50 \mathrm{mM}$ Tris- $\mathrm{HCl}, 1 \mathrm{mM}$ EDTA, $0.05 \%$ Triton X-100, 0.2 mM DTNB, $0.5 \mathrm{mM}$ oxaloacetate, and $0.1 \mathrm{mM}$ acetyl-CoA. Enzyme activity, determined at $412 \mathrm{~nm}$ with a Hitachi Spectrophotometer (USA), is reported as means \pm SEM in $\mathrm{nmol} \cdot \mathrm{min}^{-1} \cdot \mathrm{mg}$ protein ${ }^{-1}$.

Lactate dehydrogenase activity was evaluated as described by Zammit et al. (11). The assay medium consisted of $120 \mathrm{mM}$ Tris, $3.4 \mathrm{mM}$ NADH, $1 \mu \mathrm{M}$ antimiacin, $1 \%$ Triton $\mathrm{X}-100$, and deionized water, $\mathrm{pH}$ 7.4. Muscle homogenates were added to the assay mixture and the reaction was started with the addition of $2 \mathrm{mM}$ pyruvate and monitored at $340 \mathrm{~nm}$ for $10 \mathrm{~min}$, at $25^{\circ} \mathrm{C}$. Lactate dehydrogenase activity is reported as means $\pm \mathrm{SEM}$ in $\mathrm{nmol} \cdot \mathrm{min}^{-1} \cdot \mathrm{mg} \mathrm{protein}^{-1}$.

\section{Muscle total fat content}

The gastrocnemius muscle was removed and treated as described by Stansbie et al. (12). Duplicate samples were digested with $30 \% \mathrm{KOH}(\mathrm{w} / \mathrm{v})$ for $15 \mathrm{~min}$, absolute ethanol was added and the preparation was incubated for $2 \mathrm{~h}$ at $70^{\circ} \mathrm{C}$. The free fatty acids from the lipid fraction were extracted 3 times with petroleum ether and, after evaporation, the mass of the lipid present in the sample was assessed.

\section{CPT-I and CPT-II activity}

To isolate the mitochondria the muscles were minced with scissors and homogenized manually in isolation buffer (220 mM mannitol, 70 $\mathrm{mM}$ sucrose, $2 \mathrm{mM}$ HEPES, $0.1 \mathrm{mM}$ EDTA, pH 7.4). The homogenate was filtered and centrifuged twice at $1000 \mathrm{~g}$ for $12 \mathrm{~min}$. The supernatant was then centrifuged twice at 8500 $g$ for $15 \mathrm{~min}$ (13). The isolated mitochondria were suspended in a buffer consisting of 0.15 $\mathrm{mM} \mathrm{KCl}$ and $5 \mathrm{mM}$ Tris- $\mathrm{HCl}$, $\mathrm{pH} 7.5$, centrifuged at $10,000 \mathrm{~g}$ for $15 \mathrm{~min}$, resuspended in 10 $\mathrm{mM}$ phosphate buffer, $\mathrm{pH} 7.5$, frozen in liquid nitrogen, and thawed. Samples were then spectively. ultracentrifuged at $100,000 \mathrm{~g}$ for $1 \mathrm{~h}$. The resulting pellet was suspended in phosphate buffer to which Tween 20 $(1 \%, w / v)$ had been added, and stirred on ice for $30 \mathrm{~min}$ in order to separate CPT-I (membrane bound) from CPT-II. Another ultracentrifugation followed, after which the fractions containing CPT-I (pellet) and CPT-II (supernatant) were obtained. CPT activity was measured with a modification of the method described by Seelaender et al. (13). The assay medium consisted of $60 \mathrm{mM} \mathrm{KCl}, 40 \mathrm{mM}$ mannitol, $20 \mathrm{mM}$ HEPES, $0.15 \mathrm{mM}$ EGTA, $1.5 \mathrm{mM} \mathrm{KCN}, 0.5 \%$ fat-free bovine serum albumin, $42 \mu \mathrm{M}$ palmitoyl CoA, $0.35 \mathrm{mM}$ carnitine (0.6 $\mathrm{Ci}^{3} \mathrm{H}$-methylcarnitine) and approximately $0.03 \mathrm{mg}$ of the isolated enzyme fraction, or distilled water (blank). The final volume of the assay mixture was $0.5 \mathrm{~mL}$, and the $\mathrm{pH}$ 7.3. The assay was stopped by the addition of $1.5 \mathrm{~mL} 7 \%$ perchloric acid, and the acylcarnitine formed was extracted with $\mathrm{n}$-buthanol. CPT activity is reported as $\mathrm{nmol} \cdot \mathrm{min}^{-1} \cdot \mathrm{mg}$ protein $^{-1}$ in the isolated enzyme fraction.

\section{Reverse transcription and real-time polymerase chain reaction (PCR)}

Total RNA was obtained from aliquots of $100 \mathrm{mg}$ gastrocnemius muscle by Trizol reagent extraction according to manufacturer instructions. RNA concentration was determined spectrophotometrically (Beckman DU 640, USA). The reverse transcriptase and real-time PCR method was used for the estimation of the concentration of the mRNA of CPT-I and CPT-II, FABP, PPAR- $\alpha$, PPAR- $\beta$, PGC1- $\alpha$, and LPL. Complementary DNA synthesis was carried out using a 33- $\mu \mathrm{L}$ assay mix containing $3 \mu \mathrm{g}$ total RNA, $10 \mathrm{U}$ RNAse inhibitor, $2 \mu \mathrm{L}$ random primers, $2 \mu \mathrm{L}$ dNTP (10 nmol), $2 \mu \mathrm{L}$ dithiothreitol, $10 \mathrm{U} \mathrm{M}-\mathrm{MLV}$ reverse transcriptase, and $4 \mu \mathrm{L}$ $10 \mathrm{X}$ reaction buffer (100 mM Tris- $\mathrm{HCl}, 500 \mathrm{mM} \mathrm{KCl}$ and 150 $\mathrm{mM} \mathrm{MgCl}_{2}$ in nuclease-free water; Invitrogen, USA).

In a final volume of $25 \mu \mathrm{L}, 5 \mu \mathrm{L}$ cDNA was mixed with 2X SYBR Green PCR master mix (Applied Biosystems, UK) and primers (Invitrogen, Brazil). The primer sequences are presented in Table 2. Quantitative real-time PCR was carried out with an ABI 7300 Real-Time PCR Systems

Table 2. Real-time PCR primer sequences.

\begin{tabular}{llll}
\hline Gene & Sense (5'-3') & Antisense (5'-3') & Accession No. \\
\hline CPT-I & CCGAGCTCAGTGAGGACCTA & ATCTGTTTGAGGGCTTCGTG & NM_031559 \\
CPT-II & GAGCCCCTAGTAGGCCCTTA & AGGCTTCTGTGCATTGAGGT & NM_0129301 \\
FABP & ACCTCATTGCCACCATGAAC & CTTCCCTTCATGCACGATTT & NM_0125561 \\
LPL & GAACCTGGCCACATCATTTC & CAGCAAAACCTTTGTGGTGA & NM-0125981 \\
PGC1-a & TTGCCCAGATCTTCCTGAAC & TGAGGACCGCTAGCAAGTTT & NM_176075.2 \\
PPARa & CCTGCCTTCCCTGTGAACT & ATCTGCTTCAAGTGGGGAGA & NM_0131961 \\
PPAR & GAGGACAAACCCACGGTAAA & GGCCACTTCCTCTTTCTCCT & NM_013141.2 \\
\hline
\end{tabular}

CPT-I and CPT-II = carnitine palmitoyl transferase I and II, respectively; FABP = fatty acid binding protein; $L P L=$ lipoprotein lipase; $P G C 1-\alpha=$ peroxisome proliferator-activated receptor- $\gamma$ coactivator-1 $\alpha$; PPAR $\alpha$ and PPAR $\beta=$ peroxisome proliferator-activated receptor $\alpha$ and $\beta$, re- 
(Applied Biosystems). mRNA levels were determined by a cycle threshold $\left(C_{t}\right)$ value comparison method already performed and described by our group (14). For each sample, a $\Delta \mathrm{C}_{t}$ value was obtained by subtracting GAPDH values from those of the gene of interest. The average $\Delta C_{t}$ value of the control group was then subtracted from the sample to derive a $\Delta-\Delta \mathrm{C}_{t}$ value. The expression of each gene was

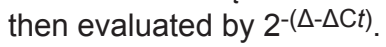

Sample protein content was assessed by the method of Lowry et al. (15). Results are reported as means \pm SEM.

\section{Statistical analysis}

Data analysis was performed using a commercial statistical package from Sigma Stat (version 3.1, Sigma Stat, SYSTAT, USA). Data are reported as means + SEM. Statistical analyses were performed using one-way ANOVA. The Tukey post hoc test was used in the event of a significant $(P<0.05) F$ ratio.

\section{Results}

During the last 4 weeks of the training $\mathrm{HI}-\mathrm{IT}$ rats and rats submitted to $\mathrm{MI}-\mathrm{CT}$ showed lower weight gain when compared to Sed $(P<0.05$; Figure 1). Muscle fat content and mitochondrial protein content did not differ among groups $(P>0.05)$. Citrate synthase activity was significantly higher in both HI-IT and MI-CT compared to Sed and in MI-CT compared to HI-IT. The enzymatic activity of lactate dehydrogenase was significantly higher only in HI-IT compared to Sed (Table 3).

The activity of CPT-I in the gastrocnemius muscle of MICT and $\mathrm{HI}-\mathrm{IT}$ was enhanced $\sim 25$ and $\sim 28 \%$, respectively, in comparison to Sed ( $P<0.05$; Figure 2). However, maximal CPT-II activity was increased solely in HI-IT compared to the Sed group $(P<0.05)$. Surprisingly, only rats training under the HI-IT protocol showed a significant increase in mRNA expression of the lipid-metabolism related proteins FABP and LPL compared to Sed (Table 4).

Plasma very low-density lipoprotein (VLDL), cholesterol, and triglyceride (TG) concentrations were all significantly lower in the HI-IT group than in the Sed group, while only plasma cholesterol levels were significantly lower in MI-CT.
Moreover, plasma VLDL concentration was decreased significantly in $\mathrm{HI}-\mathrm{IT}$ compared to $\mathrm{MI}-\mathrm{CT}(\mathrm{P}<0.05)$. Plasma insulin levels were similar among groups $(P>0.05$; Table $5)$.

\section{Discussion}

The major finding of the present study was that HI-IT resulted in the enhancement of maximal activity of the CPT complex, and a higher gene expression of proteins related to fatty acid uptake and transport. The results demonstrate that HI-IT stimulated the adaptation of steps leading to lipid oxidation.

The main component of the system is thought to be CPT-I (11). Continuous exercise training has been reported to induce enhancement of CPT-I activity and expression in humans (16). Accordingly, CPT-I maximal activity was increased in the present MI-CT protocol. Corroborating our hypothesis that high-intensity training also induces such an adaptation, the maximal gastrocnemius activities of both CPT-I and -II were increased after 8 weeks of high-intensity intermittent training.

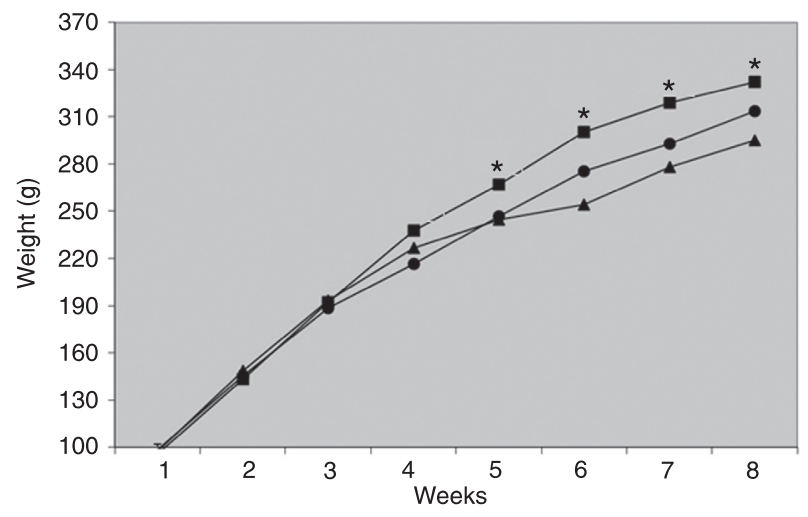

Figure 1. Variation in weight during the 8-week training protocols of sedentary (Sed; $N=5$, squares) rats and of rats subjected to moderate-intensity continuous training ( $\mathrm{MI}-\mathrm{CT} ; \mathrm{N}=10$, circles) and high-intensity intermittent training ( $\mathrm{HI}-\mathrm{IT} ; \mathrm{N}=10$, triangles). Data are reported as means \pm SEM. ${ }^{*} \mathrm{P}<0.05$ Sed compared to $\mathrm{MI}-\mathrm{CT}$ and HI-IT (one-way ANOVA).

Table 3. Fat content, mitochondrial protein content, and citrate synthase and lactate dehydrogenase maximal enzymatic activities in the gastrocnemius muscle.

\begin{tabular}{lcccc}
\hline & $\begin{array}{c}\text { Fat content }(\mathrm{mg} \\
\text { fat/g tissue; } \mathrm{N}=6)\end{array}$ & $\begin{array}{c}\text { Mitochondrial protein } \\
\text { content }(\mathrm{mg} / \mathrm{mL} ; \mathrm{N}=8)\end{array}$ & $\begin{array}{c}\text { Citrate synthase } \\
\left(\mathrm{nmol} \cdot \mathrm{min}^{-1} \cdot \mathrm{mg} \mathrm{protein}^{-1} ; \mathrm{N}=6\right)\end{array}$ & $\begin{array}{c}\text { Lactate dehydrogenase } \\
\left(\mathrm{nmol} \cdot \mathrm{min}^{-1} \cdot \mathrm{mg} \mathrm{protein}^{-1} ; \mathrm{N}=7\right)\end{array}$ \\
\hline Sed & $15.04 \pm 1.39$ & $1.44 \pm 0.10$ & $327.1 \pm 38.30$ & $1184.35 \pm 195.47$ \\
MI-CT & $16.20 \pm 1.12$ & $1.24 \pm 0.16$ & $640.5 \pm 40.9^{*}$ & $1699.17 \pm 349.65$ \\
HI-IT & $15.24 \pm 1.02$ & $1.10 \pm 0.06$ & $423.8 \pm 50.3^{* *}$ & $2166.96 \pm 205.63^{* * *}$ \\
\hline
\end{tabular}

Data are reported as means \pm SEM. Sed = sedentary; MI-CT = moderate-intensity continuous training; HI-IT = high-intensity intermittent training. ${ }^{*} \mathrm{P}<0.001$ vs Sed and $\mathrm{P}<0.01$ vs $\mathrm{HI}-\mathrm{IT}$; ${ }^{* *} \mathrm{P}<0.01$ vs Sed; ${ }^{* * *} \mathrm{P}<0.05$ vs Sed (one-way ANOVA). 

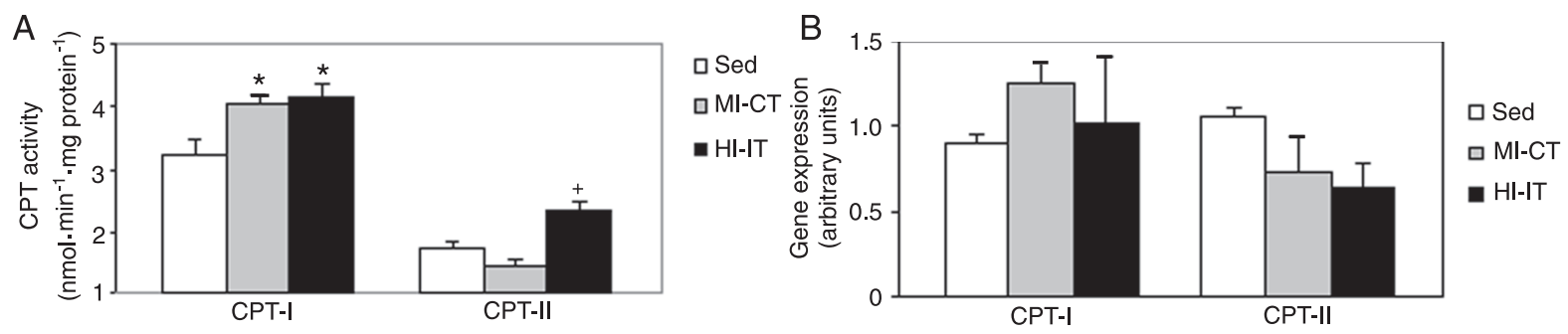

Figure 2. Carnitine palmitoyl transferase (CPT) activity $(A)$ and gene expression $(B)$ analysis in the isolated fraction of gastrocnemius muscle of sedentary (Sed) rats and of rats subjected to moderate-intensity continuous training (MI-CT) and high-intensity intermittent training (HI-IT). Data are reported as means \pm SEM $\left(\mathrm{N}=9\right.$ for maximal activity and $\mathrm{N}=5$ for gene expression). ${ }^{*} \mathrm{P}<$ 0.05 vs Sed; ${ }^{+} \mathrm{P}<0.01$ vs Sed and MI-CT (one-way ANOVA).

Since there were no detectable differences in mitochondrial protein content or in CPT-I and -II gene expression in the gastrocnemius muscle, the increase in maximal CPT-I and -II activity in the HI-IT protocol most likely reflects an enhanced catalytic capacity of these two enzymes. It is noteworthy that $16 \mathrm{~h}$ of accumulated HI-IT for 8 weeks (including adaptation protocol and resting intervals) promoted similar adaptations in the maximal activity of CPT-I and -II to those elicited by $37.6 \mathrm{~h}$ of the MI-CT protocol.

Citrate synthase activity is one of the most commonly used markers of muscle oxidative capacity because it occurs in a constant proportion with other mitochondrial enzymes (17). In agreement with the CPT-I and -II results, citrate synthase activity was enhanced in both HI-IT and MI-CT protocols. Previous studies adopting very short sprints (<10 s) failed to observe an increase in citrate synthase activity (18). In contrast, most studies, including ours, report increases in citrate synthase activity in high-intensity training, when sprint bouts lasting 15-30 s in humans (4,19-22) and rats (3) are adopted. In fact, the results of citrate synthase activity in the present HI-IT protocol are similar to those reported following 2-6 weeks of HI-IT in humans $(6,22,23)$. However, citrate synthase activity was less increased in the $\mathrm{HI}-\mathrm{IT}$ protocol than in the MI-CT protocol. This might be due to the type of fiber recruitment induced by HI-IT (mainly short twitch contraction fibers type II) (24).

MI-CT is known to increase intramuscular triacylglycerol, while data related to $\mathrm{HI}-\mathrm{IT}$ are controversial. Our results demonstrate that total muscle fat content was not altered by any of the present training protocols. However, gene expression of LPL, which is the enzyme responsible for rendering the fatty acid in lipoproteins available to the muscle, was increased in HI-IT. This may be taken as additional support of the interpretation that lipid metabolism is increased in muscle after HI-IT. This interpretation is further corroborated by the finding that plasma levels of VLDL, cholesterol, and TG were lower after the HI-IT protocol compared to the values for sedentary animals $(25,26)$.

Several studies have examined muscle metabolic and/ or performance adaptations to intermittent versus continuous training (27-29). However, in all cases the total volume
Table 4. Ratio of gene expression of molecular markers of lipid metabolism in the gastrocnemius muscle/GADPH by RT-PCR.

\begin{tabular}{llcl}
\hline & Sed & MI-CT & HI-IT \\
\hline FABP & $0.78 \pm 0.15$ & $0.21 \pm 0.08$ & $1.60 \pm 0.18^{*}$ \\
LPL & $1.18 \pm 0.44$ & $2.09 \pm 0.64$ & $4.37 \pm 0.89^{*}$ \\
PPAR $\alpha$ & $1.12 \pm 0.11$ & $1.04 \pm 0.24$ & $0.65 \pm 0.27$ \\
PPAR $\beta$ & $0.95 \pm 0.25$ & $0.56 \pm 0.04$ & $1.03 \pm 0.29$ \\
PGC1- $\alpha$ & $1.35 \pm 0.2$ & $0.94 \pm 0.39$ & $1.37 \pm 0.35$ \\
\hline
\end{tabular}

Data are reported as means \pm SEM of the ratio gene/GAPDH. Sed = sedentary; $\mathrm{MI}-\mathrm{CT}=$ moderate-intensity continuous training; $\mathrm{HI}-\mathrm{IT}=$ high-intensity intermittent training; FABP = fatty acid binding protein; $\mathrm{LPL}=$ lipoprotein lipase; PPAR $\alpha / \beta=$ peroxisome proliferator-activated receptor $\alpha$ and $\beta$, respectively; PGC1- $\alpha=$ peroxisome proliferator-activated receptor-y coactivator-1 $\alpha .{ }^{*} \mathrm{P}<$ 0.05 vs Sed (one-way ANOVA).

Table 5. Plasma concentrations of very low-density lipoproteintriglycerides (VLDL-TG), TG, cholesterol, and insulin after 8 weeks of training.

\begin{tabular}{lccc}
\hline & \multicolumn{1}{c}{ Sed } & \multicolumn{1}{c}{ MI-CT } & HI-IT \\
\hline VLDL-TG $(\mathrm{mM})$ & $0.18 \pm 0.01$ & $0.17 \pm 0.01$ & $0.14 \pm 0.01^{* *}$ \\
TG $(\mathrm{mM})$ & $0.90 \pm 0.05$ & $0.84 \pm 0.03$ & $0.69 \pm 0.05^{*}$ \\
Cholesterol $(\mathrm{mM})$ & $2.20 \pm 0.1$ & $1.70 \pm 0.10^{*}$ & $1.80 \pm 0.01^{*}$ \\
Insulin $(\mu \mathrm{U} / \mathrm{mL})$ & $5.59 \pm 0.30$ & $4.81 \pm 0.26$ & $4.71 \pm 0.25$ \\
\hline
\end{tabular}

Data are reported as means \pm SEM. Sed $=$ sedentary; MI-CT = moderate-intensity continuous training; $\mathrm{HI}-\mathrm{IT}=$ high-intensity intermittent training. ${ }^{*} \mathrm{P}<0.05$ vs Sed; ${ }^{* *} \mathrm{P}<0.05$ vs Sed and MI-CT (one-way ANOVA).

of work was similar for all groups. In agreement with the results observed in humans by Gibala et al. (6), our data indicate that, despite the difference in volume, $16 \mathrm{~h}$ of HI-IT (including resting intervals) and $37.6 \mathrm{~h}$ of MI-CT promote lower weight gain compared to sedentary animals, indicating that HI-IT may be a "time-efficient" strategy to promote weight loss. Although the cause of such efficiency of HI-IT 
is unknown, several factors may be proposed. It is expected that a higher effort intensity should recruit more fibers (30), especially of the fast twitch kind (31), increased recruitment of stabilizing muscles and increased work of the heart and respiratory muscles (32), hence resulting in higher energy

\section{References}

1. Glaister M. Multiple sprint work: physiological responses, mechanisms of fatigue and the influence of aerobic fitness. Sports Med 2005; 35: 757-777.

2. Kubukeli ZN, Noakes TD, Dennis SC. Training techniques to improve endurance exercise performances. Sports Med 2002; 32: 489-509.

3. Terada S, Yokozeki T, Kawanaka K, Ogawa K, Higuchi M, Ezaki O, et al. Effects of high-intensity swimming training on GLUT-4 and glucose transport activity in rat skeletal muscle. J Appl Physiol 2001; 90: 2019-2024.

4. Jacobs I, Esbjornsson M, Sylven C, Holm I, Jansson E. Sprint training effects on muscle myoglobin, enzymes, fiber types, and blood lactate. Med Sci Sports Exerc 1987; 19: 368-374.

5. Boutcher $\mathrm{SH}$. High-intensity intermittent exercise and fat loss. J Obes 2011; 2011: 868305.

6. Gibala MJ, Little JP, van Essen M, Wilkin GP, Burgomaster $\mathrm{KA}$, Safdar A, et al. Short-term sprint interval versus traditional endurance training: similar initial adaptations in human skeletal muscle and exercise performance. J Physiol 2006; 575: 901-911.

7. McGarry JD, Brown NF. The mitochondrial carnitine palmitoyltransferase system. From concept to molecular analysis. Eur J Biochem 1997; 244: 1-14.

8. Kawanaka K, Nolte LA, Han DH, Hansen PA, Holloszy JO. Mechanisms underlying impaired GLUT-4 translocation in glycogen-supercompensated muscles of exercised rats. Am J Physiol Endocrinol Metab 2000; 279: E1311-E1318.

9. Gobatto CA, de Mello MA, Sibuya CY, de Azevedo Jr, dos Santos LA, Kokubun E. Maximal lactate steady state in rats submitted to swimming exercise. Comp Biochem Physiol A Mol Integr Physiol 2001; 130: 21-27.

10. Bobillier Chaumont S, Maupoil V, Jacques Lahet J, Berthelot A. Effect of exercise training on metallothionein levels of hypertensive rats. Med Sci Sports Exerc 2001; 33: 724-728.

11. Zammit VA, Newsholme EA. The maximum activities of hexokinase, phosphorylase, phosphofructokinase, glycerol phosphate dehydrogenases, lactate dehydrogenase, octopine dehydrogenase, phosphoenolpyruvate carboxykinase, nucleoside diphosphatekinase, glutamate-oxaloacetate transaminase and arginine kinase in relation to carbohydrate utilization in muscles from marine invertebrates. Biochem J 1976; 160: 447-462.

12. Stansbie D, Brownsey RW, Crettaz M, Denton RM. Acute effects in vivo of anti-insulin serum on rates of fatty acid synthesis and activities of acetyl-coenzyme A carboxylase and pyruvate dehydrogenase in liver and epididymal adipose tissue of fed rats. Biochem J 1976; 160: 413-416.

13. Seelaender MC, Curi R, Colquhoun A, Williams JF, Zammitt VA. Carnitine palmitoyltransferase II activity is decreased in liver mitochondria of cachectic rats bearing the Walker 256 consumption rates compared to submaximal-intensity exercise. It is not surprising, therefore, that high-intensity intermittent exercise has been considered a good option for weight reduction both in rodent models (33) and in human obesity (34). carcinosarcoma: effect of indomethacin treatment. Biochem Mol Biol Int 1998; 44: 185-193.

14. Lira FS, Yamashita AS, Carnevali LC Jr, Gonçalves DC, Lima WP, Rosa JC, et al. Exercise training reduces PGE2 levels and induces recovery from steatosis in tumor-bearing rats. Horm Metab Research 2010; 42: 944-949.

15. Lowry $\mathrm{OH}$, Rosenborough NJ, Far AL, Randall RJ. Protein measurements with the phenol reagent. J Biol Chem 1953; 193: 265-269.

16. Tunstall RJ, Mehan KA, Wadley GD, Collier GR, Bonen A, Hargreaves $M$, et al. Exercise training increases lipid metabolism gene expression in human skeletal muscle. Am J Physiol Endocrinol Metab 2002; 283: E66-E72.

17. Green H, Grant S, Bombardier E, Ranney D. Initial aerobic power does not alter muscle metabolic adaptations to shortterm training. Am J Physiol 1999; 277: E39-E48.

18. Linossier MT, Denis C, Dormois D, Geyssant A, Lacour JR. Ergometric and metabolic adaptation to a 5-s sprint training programme. Eur J Appl Physiol Occup Physiol 1993; 67: 408-414.

19. MacDougall JD, Hicks AL, MacDonald JR, McKelvie RS, Green HJ, Smith KM. Muscle performance and enzymatic adaptations to sprint interval training. J Appl Physiol 1998; 84: 2138-2142.

20. Parra J, Cadefau JA, Rodas G, Amigo N, Cusso R. The distribution of rest periods affects performance and adaptations of energy metabolism induced by high-intensity training in human muscle. Acta Physiol Scand 2000; 169: 157-165.

21. Rodas G, Ventura JL, Cadefau JA, Cusso R, Parra J. A short training programme for the rapid improvement of both aerobic and anaerobic metabolism. Eur J Appl Physiol 2000; 82: $480-486$.

22. Perry CG, Heigenhauser GJ, Bonen A, Spriet LL. High-intensity aerobic interval training increases fat and carbohydrate metabolic capacities in human skeletal muscle. Appl Physiol Nutr Metab 2008; 33: 1112-1123.

23. Burgomaster KA, Howarth KR, Phillips SM, Rakobowchuk M, MacDonald MJ, McGee SL, et al. Similar metabolic adaptations during exercise after low volume sprint interval and traditional endurance training in humans. J Physiol 2008; 586: 151-160.

24. McAinch AJ, Lee JS, Bruce CR, Tunstall RJ, Hawley JA, Cameron-Smith D. Dietary regulation of fat oxidative gene expression in different skeletal muscle fiber types. Obes Res 2003; 11: 1471-1479.

25. Thompson PD, Cullinane E, Henderson LO, Herbert PN. Acute effects of prolonged exercise on serum lipids. Metabolism 1980; 29: 662-665.

26. Annuzzi G, Jansson E, Kaijser L, Holmquist L, Carlson LA. Increased removal rate of exogenous triglycerides after prolonged exercise in man: time course and effect of exercise 
duration. Metabolism 1987; 36: 438-443.

27. Henriksson J, Reitman JS. Quantitative measures of enzyme activities in type I and type II muscle fibres of man after training. Acta Physiol Scand 1976; 97: 392-397.

28. Gorostiaga EM, Walter CB, Foster C, Hickson RC. Uniqueness of interval and continuous training at the same maintained exercise intensity. Eur J Appl Physiol Occup Physiol 1991; 63: 101-107.

29. Edge J, Bishop D, Goodman C, Dawson B. Effects of highand moderate-intensity training on metabolism and repeated sprints. Med Sci Sports Exerc 2005; 37: 1975-1982.

30. Coyle EF. Physical activity as a metabolic stressor. Am J Clin
Nutr 2000; 72: 512S-520S.

31. Coyle EF, Sidossis LS, Horowitz JF, Beltz JD. Cycling efficiency is related to the percentage of type I muscle fibers. Med Sci Sports Exerc 1992; 24: 782-788.

32. Bates JH, Janssens S, Jiang TX, Hunter IW, Decramer M. A subtractive method for decomposing muscle tension into individual twitches. Comput Biomed Res 1988; 21: 570-578.

33. Ribeiro BL, de Mello MA, Gobatto CA. [Continuous and intermittent exercise: effects of training and detraining on body fat in obese rats]. Arch Latinoam Nutr 2004; 54: 58-65.

34. Jakicic JM. Exercise in the treatment of obesity. Endocrinol Metab Clin North Am 2003; 32: 967-980. 